\title{
A Mulher encarcerada: estigma e justiça
}

\author{
Dora Nogueira Porto ${ }^{1}$
}

Ida Raichtaler do Valle ${ }^{2}$

Resumo: Os conflitos sociais gerados na questão da desigualdade da sociedade brasileira vão aparecer de forma ampliada se o foco for a mulher encarcerada. $\boldsymbol{O}$ Estado para traçar qualquer política pública adequada precisa de dados fidedignos desta área.

Bauman chama atenção para o crescimento do "mundo dos excluídos". Isto é mais grave quando se trata do problema do gênero. A igualdade de sexo envolve modificações muito lentas e que dependem de transformações profundas que implicam em modificações que atingem elementos culturais. Muitas das mulheres estão relacionadas ao tráfico de drogas de forma indireta - presas ao tentar levar para seus companheiros encarcerados a droga ou vinculadas a pequenos roubos relacionados a sobrevivência familiar. O estigma desta mulher que veio a ser presa é violento pois uma vez no presídio elas são abandonadas e esquecidas pelos seus respectivos familiares. Aquelas que são presas e estão gravidas e porventura venham dar luz enquanto cumprem sua pena correm o e risco de não voltar a ver os seus bebês.

Engels nos diz que a desigualdade de sexo foi o primeiro antagonismo de classe presente na relação homem-mulher.

A sociedade atual está fundada sobre a injustiça distributiva e carregada de estigmas entre os quais se encontra o da mulher.

A violência urbana referida ao gênero atinge as mulheres brasileiras em geral é desproporcional às mais pobres que acaba envolvidas com questões de drogas e do crime além da violência doméstica e da violência das ruas.

Palavres Chaves: Mulher encarcerada; Desigualdade; Conflitos Sociais; Violência; Direitos Humanos.

\footnotetext{
${ }^{1}$ Professora Doutora nas áreas de Sociologia Geral e Jurídica da Faculdade de Direito da Pontifícia Universidade Católica de São Paulo

${ }^{2}$ Professora Assistente Mestre nas áreas de Sociologia Geral e Jurídica da Faculdade de Direito da Pontifícia Universidade Católica de São Paulo
} 
Summary: The social conflicts generated in the issue of the inequality of the Brazilian society will appear in an amplified form if the focus is the incarcerated woman. The State to draw up any appropriate public policy needs reliable data from this area.

Bauman calls attention to the growth of the "world of the excluded". This is more serious when it comes to the gender problem. Gender equality involves very slow modifications and depends on deep transformations that imply changes affecting cultural elements. Many of the women are related to drug trafficking indirectly - caught in trying to take their drugged inmate or tied to petty theft related to family survival. The stigma of this woman who came to be arrested is violent because once in prison they are abandoned and forgotten by their respective relatives. Those who are arrested and are pregnant and may come to light while they are serving their feathers run the risk of not seeing their babies again.

Engels tells us that gender inequality was the first class antagonism present in the malefemale relationship.

The present society is founded on the distributive injustice and loaded of stigmas among which is the one of the woman.

Urban violence related to gender affects Brazilian women in general is disproportionate to the poorest who end up involved with drug and crime issues besides domestic violence and street violence.

Keywords: Imprisoned woman; Inequality; Social Conflicts; Violence; Human Rights. 


\section{Introdução}

A democracia e o judiciário estão diretamente relacionados com o tipo de sociedade a que se referem, isto é, cultura, história, tradições, crenças etc. Segundo Dráuzio Varella ${ }^{3}$, "a sociedade brasileira que vive assustada com a violência urbana é omissa e conivente com aquela praticada pelo Estado, desde que a classe média e os mais ricos sejam poupados". Os conflitos sociais que vão sendo gerados dentro da questão da desigualdade social aparecem de uma forma ampliada no que diz respeito a mulher encarcerada. Além da violência na rua a mulher sofre com a violência doméstica. A questão prisional brasileira se transformou em um verdadeiro caldeirão pronto para explodir em qualquer momento, como ocorreu recentemente. Os motins e a barbárie dos mesmos têm crescido de uma forma assustadora e fizeram com que a presidente do STF - ministra Carmen Lúcia solicitasse (de acordo com publicação de O Estado de São Paulo, do dia 27 de fevereiro de 2018, na A3) ao CNJ dados do nosso sistema prisional. O resultado foi de que o número de presos no país é de 654.372 e destes 221.054, ou seja, um terço, aguardam julgamento "que pode ou não resultar em sentença penal condenatória". Em São Paulo atinge 15\% enquanto que em Sergipe chega a $82 \%$ da sua população carcerária sem julgamento. Os dados aí obtidos servirão de base para um censo que o IBGE pretende realizar com ajuda de entidades atuantes no meio carcerário.

Este estudo é importante para que se possa equacionar uma política por parte do Estado para atuar preventivamente nesta área.

Nossas sociedades ocidentais têm, de maneira ampla, no judiciário e na democracia os princípios ideais, ou idealizados de um mundo justo e igual. Esse mundo justo e igualitário é altamente questionável uma vez que o acesso à justiça via judiciário é restrito por questões de ordem econômica e social. O mesmo se pode pensar em relação à democracia e o que representa ante a nossa vista para além do voto. Conforme esclarece a Silvia Pimentel ${ }^{4}$ no seu posfácio da obra Ensaios Sobre Filosofia do Direito, "democracia não se restringe à vontade da maioria"; isto é "apenas parte do processo democrático". Ela implica em Direitos fundamentais que incluem "a dignidade humana”. Isso significa que além da lei escrita a questão do acesso de toda população deve ser levada em conta. Não basta que os direitos sociais estejam escritos na Constituição é preciso viabilizar

\footnotetext{
${ }^{3}$ Varella, Drauzio - Carcereiros $1^{\text {a } e d i c ̧ a ̃ o ~ S a ̃ o ~ P a u l o ~ C o m p a n h i a ~ d a s ~ l e t r a s ~ 2012, ~ p . ~ 145 ; ~}$

4 Silva Pimentel,S, "Posfácio" Pozzoli e Alvim, Marcia -Ensaios sobre Filosofia do Direito - EDUC, FAPESP - 2011 - (São Paulo)- pág. Do início do cap. 301 pg da citação 309
} 
sua aplicação. Em toda sua obra o Professor doutor André Franco Montoro ${ }^{5}$ enfatiza que que a melhor forma de desenvolvimento se dá através de possibilitar a população a participação da construção da sua própria existência com aqueles valores, concepções, conhecimentos, que lhe são próprios. Será que existe hoje a participação igualitária para todos? E as normas existentes são eficazes ou pouco servem aos objetivos que foram criadas? As respostas negativas a essas perguntas são evidentes.

A violência é um fenômeno que vem aumentando em todo o mundo nos últimos anos, gerando medo, desconfiança e isolamento: violência contra crianças, idosos e favelados, discriminação contra povos, abusos contra a mulher etc. Assim, por exemplo, conforme a cultura, democracia é um conceito oco, ou seja, como parte do mundo, como o mundo árabe, que desconhece essa proposição afirmando-se através das tradições, crenças religiosas, relações tribais, como vemos constantemente na mídia.

A questão normativa e a participação igualitária, por exemplo, ficam a dever quando se olha para os presídios femininos no Brasil. Criados nas décadas de 1930 e 1940, a instituição responsável pelos mesmos foram as Irmãs do Bom Pastor d'Angers que administravam estas prisões. Quais os princípios da criação dos mesmos? A política vigente era de que os valores próprios femininos tinham sido perdidos pelas presidiárias e portanto, necessitavam ser resgatados acrescidos dos elementos morais e religiosos. Assim se buscava a recuperação das infratoras para que elas pudessem voltar para a sociedade. Ou seja, o objetivo era a recuperação, no sentido de enquadramento dos padrões da época, o que aos poucos foi se perdendo ${ }^{6}$.

Segundo Varella ${ }^{7}$, no supracitado livro sobre os carcereiros, chama nossa atenção para o trabalho dos mesmos, daqueles que convivem com a violência e que são por ela incitados. "O vírus da violência contamina o ambiente prisional"; "a cadeia é um lugar povoado de maldade". O mesmo se pode dizer no caso das prisões femininas em que as carcereiras também se veem contaminadas por este ambiente e como em uma questão de sobrevivência acabam sendo "forjadas" por uma dureza que não faz parte de sua essência.

A ratificação de tratados Internacionais de Direitos Humanos torna cada vez mais difícil garantir uma vez que existem regras internas e políticas autoritárias vigentes em alguns países que propiciam o não cumprimento dos tratados propostos, levando a violação desses direitos.

\footnotetext{
${ }^{5}$ Montoro A.F. "Significação da Filosofia no Contexto Brasileiro" Pozzoli, L e Alvim,Marcia - Ensaios sobre Filosofia do direito-(São Paulo)- EDUC, FAPESP- 2011 pag.inicial do c..121

${ }^{6}$ Presídios femininos - Tese de Bruna Angotti apresentada em 2007 na PUC/SP

${ }^{7}$ Varella, Drauzio - Carcereiros 1 1 edição São Paulo Companhia das letras - 2012, pág 147;
} 
Os conflitos sociais gerados pela injustiça, desigualdade e exclusão apresentam no que se refere à mulher uma forma bastante grave, entre outras coisas, pelos problemas gerados pela discriminação às minorias.

Segundo Bauman ${ }^{8}$, é evidente a diferença entre os que estão no topo da sociedade e os que constituem a base. "O mundo dos excluídos cresce, diante de nossos olhos, diariamente; pessoas que não são capazes de permanecer na sociedade ativa flutuam às suas margens ou têm o sentimento de terem sido expulsas". Assim, fica perturbado o equilíbrio da sociedade e a exclusão, ou seja, ficam à margem do processo democrático.

Os próprios atores quanto a seus relacionamentos familiares, afetivos e de sociabilidade de um modo geral são, muitas vezes, objeto de violência doméstica física e verbal. À medida que a violência persiste essas mulheres ficam privadas de autoestima e acabam aceitando os maus tratos e renunciando aos seus direitos relativos à dignidade humana.

A intencionalidade de cada ação e de seus objetivos varia conforme o contexto social e econômico vivido. No caso das mulheres encarceradas, à perda da identidade sobrepõe-se o estigma; a identificação não é mais pela pessoa e sim por um número, o uniforme substitui a roupa pessoal na busca de uma negação do que se era para ter imputado alguns atributos considerados desejáveis. Essas pessoas podem aceitar ou não essa "estigmatização" e manter ocultas ou não as suas identificações.

Nesta esfera de gênero vamos citar a Dra Silvia Pimentel ${ }^{9}$ quando afirma que “existe avanços consideráveis nesta área, mas ainda grandes obstáculos impedem a igualdade dos sexos e que qualquer modificação nesse sentido é muito lenta, pois envolve modificações de padrões culturais" que se acham enraizados no processo de socialização da nossa sociedade marcada por papeis sociais baseados em um modelo de família patriarcal e machista e, portanto profundamente desiguais entre o homem e a mulher. Então “o desequilíbrio do poder no que diz respeito a questão de gênero é o responsável pela opressão da maioria das mulheres. Será possível superar este desequilíbrio? A busca por esses direitos e respeito pela dignidade humana começa por uma remoção das causas das desigualdades de gênero. Isto seria a premissa para que as mulheres tenham seus direitos respeitados.

Foi verificado que entre a população carcerária nacional reclusa um significativo número de mulheres estrangeiras. Trata-se de um braço da rede de narcotráfico

\footnotetext{
${ }^{8}$ Bauman, Z. - Babel, Editora Zahae,RJ/16 - pág. 47

${ }^{9}$ Pimentel,S C S, "Posfácio" PozzoliL e Alvim, Marcia -Ensaios sobre Filosofia do Direito - EDUC, FAPESP - 2011(São Paulo)- página do início do cap. 301 página da citação 310
} 
internacional. Essa seleção recaiu em pessoas do sexo feminino que entram nesse processo por falta absoluta de outra opção de sobrevivência. São detidas no aeroporto internacional de Guarulhos e conhecidas como "mulas" por serem simplesmente transportadores de drogas. Acrescente-se a este grupo o contingente de brasileiras que de acordo com o levantamento de Misciassi atingem $70 \%$ das encarceradas também ligadas a questão do tráfico de drogas.

A entrada no mundo do crime para as mulheres, muitas vezes se dá na própria sala de revista, onde muitas delas, apaixonadas ou chantageadas, são pegas em flagrante levando drogas e celulares. Segundo Varela ${ }^{10}$, na delegacia essas mulheres são autuadas e encarceradas e passam a cumprir as penas que podem chegar a quatro ou cinco anos, ou mais se o contato for com um líder importante. Assim, "as novatas entrarão em contato com as criminosas de carreira e aprenderão a obedecer às leis impostas pelas quadrilhas que controlam os presídios paulistas; as mais experientes farão pós-graduação em criminalidade". Ao visitar seus companheiros essas mulheres, por solicitação deles mesmos, acabam levando drogas e ao terem seus corpos vasculhados nas "revistas" ocorre o flagrante e elas passam imediatamente a se transformar em presidiárias. A partir daí ficam esquecidas dentro dos presídios femininos, de acordo com Varela, no cumprimento das penas e por abandono, pois as mulheres recebem um número muito menor de visitas que seus companheiros do sexo masculino e da própria família “que se envergonha de ter uma mulher (mãe, neta, filha ou outro familiar) em um presídio" ${ }^{11} \mathrm{O}$ estigma de mulher pesa sobre elas por parte dos valores femininos e machistas da sociedade.

As mulheres encarceradas muitas vezes estão relacionadas a pequenos crimes, ou melhor, "tentativa de roubo" ao qual muitas vezes a própria defensoria pública ao atuar na defesa da ré propõe que seja convertida em penas alternativas já que o crime segundo depoimento das próprias presidiárias estão relacionados às situações de furtos de baixo valor para atender às necessidades de sobrevivências familiares. Mas nem sempre isto é levado em consideração tanto que entre as prisioneiras encontram- se inúmeras delas relacionadas a estes "pequenos crimes”, ou seja, aguardando julgamento.

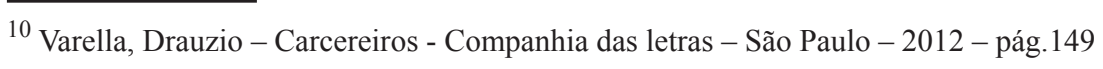

${ }^{11}$ Varella, Drauzio - Prisioneiras - Companhia das letras - São Paulo - 2017 - pág.38
} 


\section{Estigma e descrédito}

Estigma, para Goffman ${ }^{12}$, refere-se a algum atributo que torna a pessoa diferente das outras, "deixamos de considerá-la criatura comum e total, reduzindo-a a uma pessoa estragada e diminuída”.

Essa característica surge com o descrédito muito grande. No caso da mulher encarcerada, além do fato de ser mulher, carrega agora o rótulo ou estereótipo de bandida tornando-a ainda mais discriminada. Assim como Goffman usaremos o termo estigma como um atributo depreciativo sofrido pelas mulheres encarceradas.

Muitas vezes nos deparamos com o exemplo de um furto cometido por uma mulher trabalhadora, mas desempregada no momento e que afirma ter cometido o delito para garantir a subsistência dos filhos menores. Esse caso tipifica o duplo conflito da exploração no trabalho e da opressão de gênero.

No referente aos conflitos sociais gerados pela injustiça, desigualdade e exclusão destacam-se pelo maior cerceamento da justiça as mulheres estrangeiras por não terem acesso aos direitos de progressão do regime e livramento condicional.

Muitas das encarceradas nacionais são fruto do desemprego e do baixo nível de renda. Alguns dos pequenos delitos conhecidos como bagatela - furtos de pequena monta - levam muitas mulheres ao cárcere e ao consequente envolvimento com a marginalidade. No jornal Folha de São Paulo ${ }^{13}$ a defensoria pública ao atuar na defesa de uma ré declara "para esse crime - tentativa de furto - a justiça tem concedido penas alternativas. Não há necessidade de prisão". Contudo, a mesma foi decretada em função do delito de apropriação de algumas roupas e sapatos para suprir as necessidades de seis dos dez filhos.

Dentro do estigma que carrega a mulher podemos estabelecer a diferença entre os detentos e as mulheres prisioneiras apontada por Dráuzio Varela: "de todos os tormentos do cárcere, o abandono é o que mais aflige as detentas". Elas cumprem suas "penas esquecidas pelos amigos, namorados e mesmo pelos filhos". Dias de visita nos presídios masculinos são um grande acontecimento. Por mais distantes que sejam os familiares se organizam e fazem filas enormes e até dormem acampados para entrar em primeiro lugar. Já nas penitenciárias femininas o número de visitas é muito inferior e não chega a transformar em um evento para a grande maioria das internas, pois não recebem visitas.

\footnotetext{
12 Goffman, E. - Estigma, Editora Zahar, Rio de Janeiro - 1975 (pág.12)

13 Folha de São Paulo, Caderno Cotidiano, 09/08/2010
} 
Temos que questionar o porquê deste descrédito que leva a mulher a um tratamento diferenciado. Para exemplificar essa diferença Varela nos aponta um exemplo de uma mãe que visita todo final de semana o filho (usuário e traficante detido a $280 \mathrm{~km}$ da capital) e nunca foi visitar a filha que foi presa por causa do irmão (droga encontrada pela polícia em casa) que está na penitenciaria feminina da capital onde essa mesma mãe reside. ${ }^{14}$

Na TV Justiça uma reportagem sobre mulheres na prisão em 2012 nos relata que das 600 detentas no Distrito Federal, 90\% estavam ligadas ao tráfico de drogas; são as "mulas" ou pequenas traficantes levadas ao crime pelos companheiros, não sendo a grande gestora do tráfico. Claro que existem as exceções como a chamada "Maria do pó a quem era atribuído o controle do tráfico em vinte favelas de São Paulo". ${ }^{15}$ Ela ficou famosa por haver resgatado uma quantidade grande de drogas (cocaína) que se encontravam sob a guarda da Polícia Civil no Instituto Médico legal de Campinas. Procurada em todo estado ela é capturada em plena Rodovia dos Bandeirantes em uma ação cinematográfica com troca de tiros. Pouco depois ela será a protagonista de uma das raras fugas do presídio feminino de acordo com o testemunho de Varela.

Observamos que a maioria está nos presídios por falta de condições financeiras, sendo que mais de $60 \%$ das presas do sexo feminino são negras ou pardas, embora gradativamente o número de brancas venha crescendo. Na verdade, o tráfico acaba por se constituir na última alternativa de trabalho antes da prisão.

As presas grávidas têm uma ala restrita na Penitenciária Feminina de Tremembé onde executam trabalhos, frequentam escola e têm aulas de artesanato podendo inclusive vender os produtos por elas confeccionados. São desligadas destas atividades quando entregam seus bebês após seis meses para a família ou para adoção.

Com relação ao chamado Programa de Visitas Íntimas que as prisioneiras só tiveram acesso em 2002 (vinte anos depois de implantação nos presídios masculinos) apenas $10 \%$ das mesmas estão inscritas e usufruem o referido programa.

Por outro lado muitas das encarceradas chegam ao presídio grávidas ou engravidam em uma visita íntima. Isto em princípio significa receber um tratamento especial com o pré-natal, mas após dar à luz e decorridos os seis meses (antes eram só dois) estabelecidos para que cuidem do bebê em um pavilhão especial chega a parte do "martírio" segundo Varela, pois trata da separação entre a mãe e a criança. Nesta fase a falta de convívio será

\footnotetext{
${ }^{14}$ Varella, Drauzio - Prisioneiras- Companhia das letras - São Paulo - 2012 - pág.106

${ }^{15}$ Varella, Drauzio - Prisioneiras- Companhia das letras - São Paulo - 2017 - pág. 101
} 
sentido tanto pela criança, quanto pela mãe. Quando os familiares não temem condições de receber a criança ela fica na responsabilidade do Conselho Tutelar em instituições públicas e possivelmente são encaminhadas para adoção. A possibilidade dessa mãe não voltar a ver esta criança é muito grande. A solidão e as saudades do bebê levam a um alto grau de depressão "só não me suicido porque tenho esperança de recuperar meu bebê, quando sair" ${ }^{\prime \prime}$, diz uma prisioneira ao médico na consulta, pouco depois de ser separada de sua filha decorridos os seis meses do seu nascimento.

Outro tema que aborda a desigualdade da mulher dentro dos presídios é a análise das agentes penitenciárias. Quem são elas? Pertencem a outra classe social? São jovens uniformizadas que controlam os fluxos internos, elas carregam as chaves de um palmo de comprimento e abrem e trancam os portões muitas vezes ao dia. São admitidas por concurso público e pertencem a famílias de classe média baixa que optam por esse trabalho por absoluta falta de outra oportunidade. Algumas depois de algum tempo acabam pedindo demissão pela distância da família, tendo de deixar filhos, maridos ou namorados no interior. A escala de serviço é de doze em doze horas portanto não podem morar em locais distantes e convivem com um ambiente de violência constante já que são responsáveis pela contagem e por vigiar as presas. As rebeliões entre prisioneiras mulheres é menos comum, mas não é menos violenta e as primeiras reféns são as próprias carcereiras.

“Tomaram quatro guardas como reféns e começou o quebra - quebra enquanto elas eram agredidas com pedaços de pau, já machucadas foram amarradas a um botijão de gás que ameaçavam explodir no pátio ${ }^{17 ، 6}$. A rebelião só foi controlada quando depois de um dia de "loucura", sem comida e sem luz as chefes da rebelião decidiram negociar".

\section{Mulher e desigualdade}

Engels sustenta em sua obra "A origem da família, da propriedade privada e do Estado ${ }^{18}$ " que a desigualdade dos sexos foi um dos primeiros antagonismos da espécie humana. Afirma também que esse primeiro antagonismo de classe "coincide com o desenvolvimento do antagonismo entre o homem e a mulher no casamento monogâmico e a primeira opressão de classe: a do sexo feminino por parte do masculino".

\footnotetext{
${ }^{16}$ Varella, Drauzio - Prisioneiras- Companhia das letras - São Paulo - 2017 - p. 43

${ }^{17}$ Varella, Drauzio - Prisioneiras- Companhia das letras - São Paulo - 2012 - pág45 e 47

${ }^{18}$ Engels, F. - A origem da família, da propriedade e do Estado, Editora Fundamentos, Madri - 1970 - pág.83
} 
A opressão da mulher na sociedade capitalista industrial, como a que se desenvolve em São Paulo, decorre em última análise da contradição entre o desempenho da função reprodutiva tradicional e a aspiração de se realizar plenamente como ser humano.

No sistema capitalista de produção onde é necessário restringir o número de trabalhadores, o sexo torna-se o primeiro filtro no processo de competição com o objetivo de restringir o número de pessoas que podem legitimamente participar. A designação mulher justifica a marginalização de um grande número de pessoas do sexo feminino com base no papel que desempenha no processo de reprodução. Em suma, as mulheres desempenham um papel secundário nas relações de poder da época em que vivem, mas um papel principal e insubstituível na reprodução e sobrevivência da família. A mulher pertence a essa categoria de subempregado comum a outros membros da sociedade, mas com uma peculiaridade: a discriminação sexual.

Nos países periféricos a mulher além de desempenhar seu papel de dona de casa, faz outros trabalhos para completar a renda familiar. Isso em muitos casos e principalmente nos setores mais pobres faz com que a jornada de trabalho total da mulher, hoje em dia, se aproxime à dos operários ingleses do início da industrialização.

$\mathrm{Na}$ grande maioria dos países não desenvolvidos observamos que as mulheres além de serem donas de casa, muitas vezes desempenham o papel de arrimo do grupo assumindo responsabilidades de garantir e obter renda familiar para viabilizar a subsistência do núcleo como todo. Essas atividades são desenvolvidas muitas vezes através de subempregos como, por exemplo, vendedor ambulante, ou trabalhos informais sem vínculo empregatícios tais como costureira, diarista, faxineira, entre outros.

Para garantir a sobrevivência da unidade doméstica, as mulheres têm sido capazes de suportar situações muito críticas classificadas por elas mesmas de sofrimento. Assim mesmo aceitam essas situações com resignação e como "normais", não manifestando discordância com a dupla jornada e a exploração indireta que sofrem. Essa atitude de submissão não se manifesta nas lutas reivindicatórias locais por benefícios de infraestrutura. A ideologia dominante e os princípios educacionais transmitidos por séculos pela cultura excluem uma consciência dessa submissão.

De acordo com Edgar Morin ${ }^{19}$, vivemos na era planetária, o que significa buscar a justiça por meio do equilíbrio com o mundo em todos os aspectos. Esse equilíbrio só será alcançado com o cumprimento dos direitos dos cidadãos e o respeito à dignidade

\footnotetext{
${ }^{19}$ Morin, E. - Os sete saberes necessários à educação para o futuro. Editora Cortez, SP 1999.
} 
humana, o que implicaria em ter um olhar tanto sobre a mulher encarcerada quanto sobre as mulheres que trabalham nos presídios como carcereiras por também não terem o reconhecimento dos seus direitos humanos.

O sistema jurídico mundial dá uma crescente atenção aos direitos humanos que no sentido moderno surge como a decadência do antigo direito natural europeu e em estrita conexão com as "construções sócios naturais". ${ }^{20}$

\section{Justiça, leis e punição}

A justiça segundo Ost ${ }^{21}$ remete à igualdade e à legalidade, ou seja, a parte devida do outro e as partilhas fixadas por lei, numa referência à relação de honra e vergonha, que temos em relação ao outro. O respeito compreende "a estima de si, respeito pelo outro, respeito humano e respeito à lei”.

Citando A.France (Le Lys Rouge, Gallimard, Paris, pág.480/XXII) Ostnos reporta que enquanto a sociedade estiver fundada sobre a injustiça distributiva profundamente desigual e carregadas de estigmas às minorias, as leis terão por função sustentar este quadro geral de injustiça. Na visão deste contexto as leis serão reconhecidas e mais respeitadas na medida em que contribuírem para a manutenção do status quo.

Dworkin ${ }^{22}$ nos apresenta o seguinte dilema sobre as leis más, que mesmo sendo más, as leis continuam. Segundo esse autor "responsabilidade moral jamais se consuma; reinterpretamos constantemente nossos conceitos à medida que os utilizamos".

Assim, considerando que são válidas essas leis, o juiz defronta-se com o dilema de decidir usar o que diz na integra a lei escrita ou fazer uso da sua interpretação para adequá-la à realidade e à situação social dos réus.

Dizer que no nosso país hoje a mulher tem os mesmos direitos de acordo com a lei não corresponde à realidade. Isso é o que consta na lei escrita, mas considerando a realidade desigual e os estigmas de cada grupo social, é necessário se buscar outros caminhos para superar a problemática da desigualdade.

Uma experiência ou um novo caminho é apontado pela chamada "Justiça restaurativa" 23 que é definida como "processo focado em reparar os danos provocados

\footnotetext{
${ }^{20}$ Bauman, Z. - Babel, Editora Zahae,Rio de Janeiro- 2016 - pág. 47

${ }^{21}$ Ost, F. - Contar a Lei - Editora Unisinos da Universidade Vale dos Sinos, Rio Grande do Sul - 2007 - pág.64;

22 Dworkin, R. - A raposa e o porco espinho, Editora Martins Fontes, São Paulo 2014 - pág. 180;

${ }^{23}$ Giddens, A e Sutton, P W. - Conceitos essenciais da Sociologia. Editora Unesp, São Paulo - 2014 - pág. 290 a 291
} 
às vítimas de crimes e desvios e requer a participação de todos os envolvidos”. Trata-se de uma experiência em que se atua fora do sistema judicial punitivo (evitando o sistema carcerário superlotado e ineficaz). Foi testado na Nova Zelândia e na Austrália e os juízes utilizam uma espécie de mediação entre as partes (vítima e réu). Não se exclui aí a probabilidade de punição em caso de crimes graves e ou muitos violentos.

Sendo este tipo de justiça algo relativamente recente estando ainda sujeito a avalições sistemáticas e não conclusivas teríamos que utilizá-lo com reservas. Acrescentese a isto a realidade de países desenvolvidos e o alto grau de distribuição de renda e educação.

O direito não se estabiliza, isto é, não para no tempo, segundo Luhmann, ${ }^{24}$ no sentido de que o que é válido uma vez seja válido sempre, não se mantendo imutável. Há mudança e tem que ter prevista uma compensação. Assim, a validade jurídica não é algo estático, relativamente invariável, mas algo dinâmico.

No filme Sem Pena, de François C.K.Ravachol (2015), temos o depoimento de um ex-soldado da PM que, desiludido com a justiça, comenta que o roubo de um shampoo e de um banco estão no mesmo patamar. Além do que o comportamento do soldado muda conforme "o cara", se está de havaiana, fusca ou num audi.

A lei no entender de vários entrevistados é muito bem "bolada" no papel, mas não é cumprida e o sistema carcerário é desumano e como diz um deles: "um animal morre na prisão, só o ser humano suporta", "é uma escola do crime".

O crime é social e não individual uma vez que a maioria se dá na relação extrínseca com a sociedade e não tanto na esfera da sexualidade, da tara. Fazendo uma comparação com nosso cotidiano, um depoente diz que colar prejudica a sociedade toda porque você vai formar pessoas incompetentes enquanto que roubar prejudica só uma pessoa.

Segundo um entrevistado no filme, houve uma situação em que algumas pessoas ficaram nove horas presas no camburão e lá tiveram que fazer suas necessidades; então, segundo o mesmo, se o Estado não respeita o direito das pessoas, a facção - PCC defende, contratando advogados e tirando os presos da prisão, mas depois "na rua" vão cobrar presado.

Somos a terceira população carcerária do mundo, só atrás da China e dos Estados Unidos. Esta população é composta de jovens pobres, geralmente negros e traficantes, embora sem vínculos com grupos maiores do tráfico.

\footnotetext{
${ }^{24}$ Luhmann, N. - O direito na sociedade, Editora Martins Fontes, São Paulo - 2016
} 


\section{Considerações finais}

Quando buscamos entender nosso tempo e os ideais que nortearam nossos juízos, vemos uma crescente desigualdade, exclusão e injustiça populacional.

Como pondera De $\mathrm{Masi}^{25}$ os recursos planetários crescem, mas não se sabe distribuí-los; assim também economistas como J.Stiglitz, Piketty e outros demonstram através de modelos matemáticos essas diferenças.

Do início de nosso artigo nos perguntamos o que propor como políticas públicas ao Estado democrático de modo a equacionar ou minimizar tais desigualdades. $\mathrm{O}$ maior problema em termos políticos é o desaparecimento de líderes renomados e o declínio das ideologias. Hoje não contamos mais com um apoio e uma direção a seguir; a sociedade atual não tem mais direcionamento e nem modelo ideal a seguir.

No entender de De Masi $^{26}$ vivemos numa sociedade desorientada devido aos "saltos de época"; tais saltos provêm de mudanças simultâneas no trabalho, na riqueza, no poder e no saber e atingem gerações inteiras. Essa profunda desorientação na sociedade pós-industrial gera um "sentimento suspenso entre surpresa e pânico"27.

Talvez essa desorientação ajude a explicar a depressão em países, como o nosso, onde convivem o demasiado novo e o demasiado velho e que acabam por se traduzir em medos variados que vão das guerras e epidemias à solidão, medo da morte e do além.

Essa sensação geral de desorientação é a soma de múltiplas desorientações setoriais, como no caso do judiciário e do encarceramento feminino, determinados por causas próprias.

Voltando os olhos para nossa realidade de violência urbana para o foco desta reflexão, temos que "a violência de gênero é um flagelo que de uma forma ou outra atinge todas as mulheres brasileiras, mas o ônus se concentra de maneira desproporcional entre as mais pobres e negras, como constatam as estatísticas" ${ }^{28}$. A precária escolaridade, as deficiências de moradia e de relações familiares acabam por contribuir para a gravidez na adolescência, e o envolvimento de jovens no crime e na dependência de drogas e suas consequências naturais - violência doméstica e das ruas; estupros etc.

\footnotetext{
${ }^{25}$ De Masi, Domenico - Alfabeto da sociedade desorientada, Editora Objetiva, São Paulo, 2017

${ }^{26}$ De Masi, Domenico - Alfabeto da sociedade desorientada, Editora Objetiva, São Paulo, 2017 - pág.93

${ }^{27}$ De Masi, Domenico - Alfabeto da sociedade desorientada, Editora Objetiva, São Paulo, 2017 - pág.94

${ }^{28}$ Varella, Dráuzio - Prisioneiras- Companhia das letras - São Paulo - 2017 - pág. 268
} 
Esse contexto se deve também à desorientação social, política e ideológica acima referida. Do ponto de vista econômico, o crime organizado é um capitalismo com controle centralizado em que o topo da hierarquia é cem por cento masculino. Assim as mulheres ficam submissas a esse comando dos homens que é feito de forma muito pesada.

Não poderíamos terminar este artigo sem fazer referência a profunda desigualdade com que é aplicada a lei no Brasil. O exemplo é apontado pelo Dr.Dráuzio ${ }^{29}$ quando ele houve a revolta de uma presidiaria que afirma; "eu fui presa na portaria de uma cadeia quando levava cinquenta e cinco gramas de cocaína pedida por meu marido e estou até hoje presa". ${ }^{30}$ Ela faz referências a um homem jovem que foi preso com cento e cinquenta quilos de droga e cuja mãe (desembargadora) conseguiu que o mesmo fosse solto para receber um tratamento de um "transtorno" psiquiátrico e difícil diagnostico em uma clínica particular. As diferenças de tratamento em um caso e outro é marcante: temos aí a de classe social e a de sexo.

\section{Bibliografia}

Bauman, Z. - Babel - Rio de Janeiro - Editora Zaha -2016- pág. 47

De Masi, Domenico - Alfabeto da sociedade desorientada - São Paulo - Editora Objetiva -2017 - pág.93

De Masi Domenico - Alfabeto da sociedade desorientada - São Paulo - Editora Objetiva - 2017 - pág.94

Dworkin, R. - A raposa e o porco espinho - São Paulo - Editora Martins Fontes - SP 2014 - pág. 180;

Engels, F. - A origem da família, da propriedade e do Estado, Editora Fundamentos, Madri - 1970 pág. 83

Benites, Afonso - Juíza manda prender desempregada, mãe de 10 filhos, por calote de fiança - São Paulo - 2010 - Artigo da Folha de São Paulo, Caderno Cotidiano - pag C3 publicado em 09/08/2010

Giddens, A e Sutton, P W. - Conceitos essenciais da Sociologia - São Paulo - Editora Unesp, SP - 2015 - pág. 290 a 291

\footnotetext{
${ }^{29}$ Varella, Dráuzio - Prisioneiras- Companhia das letras - São Paulo - 2017 - pág. 43

${ }^{30}$ Varella, Dráuzio - Desigualdade Judiciária - São Paulo - 2017 - Artigo publicado na Folha de São Paulo em $05 / 08 / 2017$.
} 
Goffman, E. - Estigma - Rio de Janeiro - Editora Zahar, 1975/(pág.12)

Luhmann, N. - O direito na sociedade - São Paulo - Editora Martins Fontes, 2016

Montoro A.F. “Significação da Filosofia no Contexto Brasileiro" Pozzoli, Le Alvim,Marcia - Ensaios sobre Filosofia do direito-(São Paulo)- EDUC, FAPESP- 2011 pag.inicial do c..121

Morin, E. - Os sete saberes necessários à educação para o futuro - São Paulo - Editora Cortez, 1999

Ost, F. - Contar a Lei - Rio Grande do Sul - Editora Unsinos, da Universidade Vale dos Sinos, Rio Grande do Sul -2007 - pág .64;

Pimentel,S C S, "Posfácio" PozzoliL e Alvim, Marcia -Ensaios sobre Filosofia do Direito - EDUC, FAPESP - 2011- (São Paulo)- pág. Do início do cap. 301 pg da citação 310

Pimentel,S C S, "Posfácio" PozzoliL e Alvim, Marcia -Ensaios sobre Filosofia do Direito - EDUC, FAPESP - 2011- (São Paulo)- pág. Do início do cap. 301 pg da citação 310

Varella, Drauzio - Carcereiros - São Paulo - Companhia das letras - 2012 - pág.149

Varella, Drauzio - Prisioneiras - São Paulo - Companhia das letras - 2017 - pág..38

Varella, Drauzio - Prisioneiras - São Paulo - Companhia das letras - 2017-pág.101

Varella, Drauzio - Prisioneiras - São Paulo - Companhia das letras - 2017 - pág.43

Varella, Drauzio - Prisioneiras_São Paulo - Companhia das letras - 2017 - pág.45 e 47

Varella, Drauzio - Prisioneiras - São Paulo - Companhia das letras - 2017 - pág.106

Varella, Drauzio - Carcereiro - São Paulo - Companhia das letras - 2012 - pág 145

Varella, Drauzio - Carcereiro - São Paulo - Companhia das letras - 2012 - pág 147

Varella, Drauzio - Carcereiro - São Paulo - Companhia das letras - 2012 - pág 268

Recebido em 07/11/2018

Aprovado em 20/12/2018 